\title{
Las ciencias sociales frente al avance de las "nuevas" derechas en América Latina en el siglo XXI
}

\author{
Mónica Nikolajczuk* \\ Florencia Prego*
}

\section{Resumen}

La problematización de las derechas y las "nuevas" derechas en América Latina ha recobrado una importancia vital en la coyuntura histórica actual. Desde el campo de las ciencias sociales se han abonado distintas tesis sobre el carácter novedoso (o no) de estos sectores y han proliferado una serie de análisis sobre la cuestión desde una mirada de conjunto.

En este contexto, el objetivo de este artículo es aportar una descripción y un análisis de las discusiones académicas que abordan las "nuevas" derechas en América Latina en el siglo XXI con el fin de indagar en los núcleos de consenso y disenso que tiñen la literatura reciente sobre la temática.

A lo largo del trabajo problematizaremos cuatro ejes estructurantes: una matriz conceptual que rescata la condición relacional e históricamente situada entre derechas e izquierdas y la diada igualdad-desigualdad como elemento constitutivo de la distinción; la cuestión de los sujetos, es decir, los análisis respecto de la composición y la representación; y la relación entre derechas y democracia. Finalmente, esbozaremos los avances hacia una conceptualización de las derechas latinoamericanas del siglo XXI y las discusiones en torno a su novedad.

Palabras clave: América Latina, Democracia, Nuevas derechas, Ciencias sociales, Siglo XXI

\footnotetext{
* Licenciada en sociología por la Facultad de Ciencias Sociales, Universidad de Buenos Aires. Maestranda en Estudios Sociales Latinoamericanos por la Universidad de Buenos Aires. Becaria doctoral Conicet. Investigadora en formación del UBACyT "Think tanks, ideas y política en Argentina, Brasil y Paraguay (2002-2020)" dirigido por Lorena Soler y del Grupo de Trabajo CLACSO "Intelectuales y política" dirigido por Lorena Soler, Alfredo Falero y Charles Quevedo.

* Licenciada en sociología por la Facultad de Ciencias Sociales, Universidad de Buenos Aires. Maestranda en Estudios Sociales Latinoamericanos por la Universidad de Buenos Aires. Investigadora en formación del UBACyT "Think tanks, ideas y politica en Argentina, Brasil y Paraguay (2002-2020)" dirigido por Lorena Soler y del Grupo de Trabajo CLACSO "Intelectuales y política" dirigido por Lorena Soler, Alfredo Falero y Charles Quevedo.
} 


\section{Abstract}

The problematization of the rights and the "new" rights in Latin America has regained vital importance in the present historical conjuncture. From the field of social sciences different theses on the novelty character (or not) of these sectors have been fertilized and a series of analyzes have proliferated.

In this context, the main goal of this article is to provide a description and an analysis of the academic investments that address the "new" rights in Latin America in the 21st century, giving an account of the existing debates in order to investigate the nuclei of consensus and dissent on the subject.

Throughout this article four structuring axes are considered: a conceptual matrix that rescues the relational and historically included condition between the right and left and the diada equality-inequality as a constitutive element of the distinction; the analysis of composition and representation of right wing gorups; and the relationship between the rights and democracy. Finally, we will outline the progress towards a conceptualization of the Latin American rights of the 21st century and the discussions around its novelty.

Keywords: Latin America, Democracy, New Rights, Social Sciences, 21st Century

\section{Las derechas en el contexto político latinoamericano. Una breve introducción desde el presente histórico}

En la coyuntura histórica actual, la problematización de las derechas y las "nuevas" derechas en América Latina ha recobrado una importancia vital. Desde el campo de las ciencias sociales se han abonado distintas tesis sobre el carácter novedoso (o no) de estos sectores y han proliferado una serie de análisis que problematizan la cuestión desde una mirada de conjunto. Esto último es de vital importancia puesto que, como advierte McGee Deutsch (2005), hasta este el momento sólo Romero en su trabajo El pensamiento político de la derecha en América Latina del año 1970 había aprehendido el fenómeno a escala regional. Los estudios que le sucedieron se anclaron en los casos nacionales, dejando de lado las relaciones entre las derechas latinoamericanas en clave comparada.

En este marco, el objetivo de este artículo es aportar una descripción y un análisis de las discusiones académicas que abordan las "nuevas" derechas en América Latina en el siglo XXI. Distintos interrogantes guían nuestro análisis: ¿De qué hablamos cuando nos referimos a las derechas? ¿Existe una nueva derecha en América Latina en el siglo XXI? ¿Cuáles son las continuidades y las rupturas advertidas respecto a las derechas del 
siglo XX? ¿Qué elementos resalta la literatura académica como "novedoso"? ¿Cuál es su modo de abordaje?

Desde una mirada social e histórica podemos advertir un proceso de reconfiguración constante y continuo de las derechas latinoamericanas. Haciendo un breve racconto, en la década del veinte, tras el triunfo de la Revolución Rusa y el fin de la Primera Guerra Mundial, las fuerzas de derechas asumieron una impronta eminentemente anticomunista en nuestra región, siendo los ejemplos más representativos la Legión Cívica en Argentina, los revisionismos del Rio de la Plata y el revisionismo chileno. Con la crisis económica de la década del treinta construyó un lenguaje fuertemente antiliberal y, en el marco de la Segunda Guerra Mundial, adoptaron en algunos casos una impronta antisemita al calor de los fascismos europeos (entre los ejemplos más paradigmáticos están el nazismo chileno y el integralismo brasileño). En la coyuntura de la Guerra Fría, se impuso un férreo nacionalismo y recrudecieron los valores anticomunistas. Asimismo, la llegada al poder de los denominados populismos clásicos de la mano de Lázaro Cárdenas (1934-1940), Getulio Vargas (1950-1954) y Juan Domingo Perón (1946-1955) como así también la Revolución Cubana (1959), activaron un lenguaje de disputa específico y estrategias de acción congruentes con la correlación de fuerza imperante. De esta manera, las derechas latinoamericanas se volvieron eminentemente liberales, anticomunistas y antipopulistas.

La implementación de la Doctrina de Seguridad Nacional (DSN) en la década del sesenta y setenta profundizó el registro de las derechas regionales en la medida que habilitó un escenario de acción y pensamiento ligado con la construcción del enemigo interno y su asociación a las Dictaduras Institucionales de las Fuerzas Armadas o a gobiernos autoritarios que impusieron el terrorismo de Estado en América Latina, culminando hacia mediados de la década del ochenta. Sin embargo, la transición a la democracia implicó nuevamente la adaptación de la derecha a la nueva realidad histórica.

El derrumbe del socialismo real figurado en la caída del Muro de Berlín (1989) y en la posterior disolución de la URSS (1991) implicó un cambio en las adhesiones 
político-ideológicas dando lugar a el surgimiento de marcos de referencias más difusos, pero también la victoria de los ideales del pro-mercado y el Estado mínimo.

La derrota de los movimientos revolucionarios de izquierda y el fin de los denominados populismos habilitaron el ingreso pleno del neoliberalismo en la región y con él, la implementación de las políticas del Consenso de Washington. En este marco, de la mano del andamiaje partidario tradicional, las derechas latinoamericanas llegaron al poder vía elecciones y aplicaron reformas estructurales que tendieron a la redistribución regresiva del ingreso y a minimizar la capacidad del Estado en el control y organización de la economía. Los casos más representativos fueron Carlos Menem (1989-1999) en Argentina, Alberto Fujimori (1990) en Perú -paradójicamente también Ilamados populistas- Víctor Paz Estenssoro (1985-1989) y Gonzalo Sánchez de Lozada (1993-1997y 2002-2003) en Bolivia, Fernando Henrique Cardoso (1995-2003) en Brasil, Jamil Mahuad Witt (1998-2000) en Ecuador, y Juan Carlos Wasmosy (1993-1998) en Paraguay.

En los albores del siglo XXI, el paradigma neoliberal había tensado hasta el límite la gobernabilidad, decantando en una crisis que superó la dimensión económica y financiera hasta penetrar la escala política - con sus consecuentes crisis de representación - poniendo entre paréntesis el andamiaje institucional establecido. Las consecuencias de las reformas estructurales a escala societal impactaron en la profundización de la desigualdad. Esta situación sentó las condiciones objetivas y subjetivas para la emergencia, en algunos países, de gobiernos progresistas denominados alternativamente como posneoliberales (Sader, 2009), progresistas (Svampa, 2017), nueva izquierda (Chávez, Rodríguez Garavito y Barrett, 2008), antineoliberales (Quiroga, 2010), o populistas (Laclau, 2006). Más allá de las distintas denominaciones y de la heterogeneidad de los procesos, en la integralidad del fenómeno podía reconocerse la alteración de la correlación de fuerzas que suponía un nuevo signo de la realidad política latinoamericana. En el marco de estas experiencias destacamos los casos de Venezuela, Argentina, Brasil, Bolivia, Ecuador, y, en menor medida, Uruguay y Chile.

En este contexto, las derechas latinoamericanas - tanto las que se mantuvieron en la dirección de los gobiernos, como también las que se encontraban en la oposición - se 
vieron condicionadas por el ciclo de proyectos posneoliberales y compelidas a reconfigurar sus estrategias de acción e intervención política; sus prácticas, su discurso y su lenguaje. Algo había cambiado en términos objetivos y subjetivos en la región y fueron capaces de realizar dicha lectura y adaptarse al cambio de época, de allí el interés por problematizar la novedad instaurada a partir del reconocimiento de su pragmatismo.

Actualmente se discute el supuesto fin de ciclo progresista en América Latina, dada la recuperación del poder político por parte de las fuerzas de derecha. El ascenso al poder - ya sea por intermedio de golpes de Estado o a través de un proceso electoral - de Horacio Cartes (2013-2018) y Mario Abdó Benitez (2018) en Paraguay; Mauricio Macri en Argentina (2015); Michel Temer en Brasil (2016); Jimmy Morales en Guatemala (2016); Sebastián Piñera en Chile (2010 y 2018); Lenin Moreno ${ }^{1}$ en Ecuador (2017); e Iván Duque en Colombia (2018), presenta un nuevo escenario que nos insta a problematizar el avance de las derechas latinoamericanas. Sin embargo, es preciso advertir los límites y las potencialidades, las rupturas y las continuidades para poder pensar las condiciones de posibilidad y realización de una alteración en la correlación de fuerzas que consagre su despliegue y sentencie el repliegue de los proyectos progresistas y populares.

En paralelo a las reconfiguraciones históricas, el campo académico trató de explicar el fenómeno a través de categorías analíticas que tuvieran capacidad heurística y que, a su vez, pudieran situar históricamente el fenómeno. En este sentido, es importante advertir que la discusión y producción teórica dialoga vis a vis con una realidad política cambiante.

Nuestro recorte, sin ser exhaustivo, intenta plasmar una reconstrucción de la literatura académica sobre el tema en torno a cuatro núcleos estructurantes. El primero se refiere a la definición de las derechas como posiciones en el espectro políticoideológico que mantienen una condición relacional con las izquierdas y, por lo tanto, un

\footnotetext{
${ }^{1}$ Si bien Lenin Moreno llegó a la presidencia de la mano de Alianza País (AP) y con el apoyo de Rafael Correa, las políticas sociales y económicas que lleva a cabo desde su asunción van en línea con la desregulación de la economía, la reducción del gasto público y endeudamiento externo. Asimismo, propicia una campaña de persecución de líderes políticos relacionados con la gestión anterior; entre ellos, contra el mismo ex presidente.
} 
carácter históricamente situado. A su vez, en este núcleo se analizan los debates en torno a la díada igualdad-desigualdad y su impacto en la conformación de ambas fuerzas. Estos elementos constituyen los principales núcleos de consenso y son retomados en bastas contribuciones académicas. El segundo ahondará en el modo en que ha sido problematizada la cuestión de los sujetos, es decir, los análisis respecto de la composición y la representación de las fuerzas de derecha. En tercer lugar, daremos cuenta del abordaje por parte de la bibliografía trabajada de la relación democraciaderechas. Hacia el final realizaremos algunas reflexiones preliminares sobre el proceso de reconstrucción realizado y los intentos por avanzar hacia una conceptualización sobre del carácter novedoso (o no) de las derechas en América Latina.

\section{La matriz conceptual de los estudios sobre las derechas. El carácter relacional e históricamente situado y la diada igualdad- desigualdad}

Gran parte de los aportes recientes realizados desde las ciencias sociales sobre las derechas en el siglo XXI reponen una matriz conceptual basada en la producción intelectual del politólogo Norberto Bobbio. En Derecha e Izquierda (1994) el autor propone dos variables que fueron retomadas en la posterior literatura sobre el tema: la condición relacional, por tanto, históricamente situada, entre izquierdas y derechas y la posición respecto de la diada igualdad-desigualdad como parámetro para distinguirlas. El objetivo de este apartado será dar cuenta, dentro del corpus de trabajos que conforman este artículo, de la existencia de esta matriz conceptual y la forma en que es retomada y problematizada por los autores.

En cuanto a la primera variable (la condición relacional entre derecha e izquierda) debemos remitirnos al origen de la división izquierda-derecha que nos conduce al hecho fortuito de la Asamblea Nacional que nace tras la Revolución Francesa, donde la división espacial de la misma (de lado izquierdo los miembros del Tercer Estado, o los comunes, y del lado derecho el Primer y Segundo Estado en manos del clero y la nobleza) devino en el mecanismo de distinción para nominar la polarización de las fuerzas políticas. 
La derecha como la izquierda no pueden pensarse como conceptos estáticos sino cambiantes, y se definen a partir de su carácter relacional e históricamente situado. Para Norberto Bobbio (2014) dicha relación constituye una díada antitética, exclusiva (ningún movimiento ni doctrina puede ser de izquierda y derecha al mismo tiempo) y exhaustiva (un movimiento o doctrina únicamente puede ser de derecha o de izquierda): “Derecha e izquierda son dos términos antitéticos que, desde hace más de dos siglos, se emplean habitualmente para designar el conflicto entre las ideologías y los movimientos en que está dividido el universo, eminentemente conflictivo, del pensamiento y las acciones políticas" (pp.33). Sin embargo, en el marco de la crisis de las ideologías redundaron cuestionamientos y posiciones que rebatían dicha distinción, so pretexto de la falta de valor heurístico y clasificatorio. Ante esto, Bobbio (2014) sostuvo que la problematización y construcción de la díada derecha-izquierda no se reduce meramente a una cuestión ideológica, sino a los programas contrapuestos, a las diferentes acciones políticas, como así también a los distintos intereses y las distintas valoraciones que mueven y promueven.

Es necesario destacar aquellos aportes que vinculan la dimensión histórica con el proceso de construcción conceptual dado que, tal como plantea Somers (1996), los conceptos son palabras en su contexto. Ratificando el carácter eminentemente histórico y su deriva metodológica, el estudio de las derechas en cada coyuntura requiere de una sólida investigación empírica.

En la década del setenta José Luis Romero, en su clásico estudio ya mencionado sobre las derechas latinoamericanas, reconocía la necesidad de caracterizar a los grupos sociales y de pensamiento político que integran las fuerzas que se clasifican como derecha (grupos señoriales, burgueses, oligarquías liberal burguesas), adscribiendo a un imprescindible análisis empírico para cada situación histórica. Pese a la controversial clasificación, la perspectiva de Romero tiene un doble propósito: resaltar la historicidad del fenómeno y considerar el problema desde una perspectiva histórica que no sea ajena a la conceptualización (Giordano, 2014).

Impulsado por una propuesta metodológica similar, Octavio Rodríguez Araujo (2004) advierte que "sólo un análisis detallado, para cada país y cada momento, nos permitiría ver las diferencias entre las políticas de los diversos partidos o coaliciones de 
partidos en el poder" (pp.37). Para el autor, tanto derecha como izquierda son conceptos relativos que han cambiado de acuerdo con las tradiciones, el tipo de sociedad y el proceso de reconfiguración del poder. De esta manera, son relativos tanto al momento histórico como a la perspectiva política, ideológica y moral. En la misma dirección, Torquato Di Tella (2004) afirmaba "hablar de derecha o de izquierda es referirse a posiciones relativas. No hay un conjunto de actitudes o ideas que sean siempre de izquierda o permanentemente de derecha: todo depende del país del cual se hable" (p.13) o de las coaliciones que puedan formarse en dichos países.

La construcción del concepto involucra situaciones históricas, conflictivas y controversiales; por lo tanto, la historicidad es inherente al fenómeno y al concepto (Giordano, 2014). Esto permite reconocer la imposibilidad de construir un concepto universal y ahistórico de las derechas.

El segundo de los elementos que conforma esta matriz conceptual es la posición de derechas e izquierdas en cuanto a la diada igualdad-desigualdad. Nuevamente, Bobbio (2014) reconoce allí la condición orgánica de la distinción: mientras la izquierda promueve y tiende a la igualdad (lo que no equivale al igualitarismo) la derecha profundiza la desigualdad.

Waldo Ansaldi (2017) afirma que el núcleo duro (orgánico) de las derechas es la cuestión de la relación igualdad-desigualdad: "Las derechas pueden cambiar en varias cuestiones, pero en ese punto son inmutables" (pp.9). En la misma línea, Juan Pablo Luna y Cristóbal Rovira Koltwasser (2016) conceptualizan a las derechas como una posición política que conlleva la desigualdad como algo natural y fuera del ámbito de la competencia del Estado. Entienden que la distinción en torno a la desigualdad proporciona una herramienta esencial para asignar plataformas programáticas a lo largo del espectro izquierda-derecha y del tiempo: "Como menciona Bobbio en su célebre trabajo, la distinción no se enraíza en el plano exclusivamente ideológico, sino que "indican programas contrapuestos respecto a muchos problemas cuya solución pertenece, habitualmente, al ámbito de la acción política” (pp.36- la traducción es nuestra-).

Ello suscita otra discusión acerca del carácter natural y social inscripto en esta distinción orgánica: para la izquierda la desigualdad es social, por lo tanto, puede 
erradicarse, mientras que para la derecha la desigualdad es natural y por ende inmodificable. Retomando el primer eje de este núcleo, es preciso atender a las condiciones sociales e históricas de esta distinción para no caer en abstracciones y comprender que, en el marco de las sociedades capitalistas, la desigualdad es un factor estructural y a su vez, condición necesaria para su reproducción.

Partiendo no solo la díada igualdad-desigualdad sino también el condicionamiento que ejerce el modo de producción, Rodríguez Araujo (2004) sostiene que la derecha promueve la desigualdad (el no-igualitarismo) mientras la izquierda tiende a la igualdad (igualitarismo), lo que equivaldría a hablar, respectivamente, de capitalismo y socialismo.

En ese sentido, el autor señala que esta tendencia puede observarse en la producción de políticas públicas. Por lo tanto, un gobierno que no promueve mayor igualitarismo o que refuerza las desigualdades sociales es un gobierno de derecha. A su vez, Cannon (2016) destaca la centralidad de la desigualdad para definir izquierda y derecha, pero advierte la necesidad de incluir el estudio de clases dado que "cada opción de política tiene resultados implícitos y explícitos en favorecer algunas clases sobre otras y, por lo tanto, la clase y el papel de las élites deben ser centrales en cualquier discusión sobre la derecha" (p.27- la traducción es nuestra-).

El trabajo de Sandra McGee Deutsch (2005) se ha convertido en una referencia en el estudio de las derechas a escala regional. En el mismo, la autora afirma que la díada status quo-cambio, devenido en las personificaciones conservadores-progresistas, juega un papel estructurante; también sostiene que las mismas se consolidan en reacción a todas las tendencias igualitarias y liberadoras del momento ya que temen que debiliten el "respeto a la autoridad, la propiedad privada, las tradiciones que valora y las particularidades de la familia, el terruño y la Nación" (pp.21). En suma, no importa cuáles sean las tendencias niveladoras y liberadoras, las derechas se construyen en torno a su oposición.

Como puede observarse, esta matriz conceptual basada en los aportes de Norberto Bobbio rescata la relación históricamente situada de las derechas y las izquierdas y la apuesta por demostrar que el núcleo orgánico de las mismas reside en su posición respecto de la diada igualdad-desigualdad. 


\section{La cuestión de los sujetos: entre la composición y la representación}

En rigor, existen dos preguntas que problematizan - ya sea de manera central o subrepticiamente- la cuestión de los sujetos en los estudios sobre las derechas. La primera de ellas refiere a la composición, es la pregunta por el quiénes conforman fuerzas de derecha.

En línea con esta distinción destacamos la caracterización de Waldo Ansaldi (2017) para quien "derecha es la posición política de la burguesía, en primer lugar, pero una parte importante de la base social y política de derecha no ha sido ni es burguesa. En otros términos: el pensamiento y las prácticas de derechas se han expandido históricamente entre, e incluso ganado a, importantes contingentes de las clases subalternas" (2016:8). Lo que indica uno de los principales desafíos intelectuales y políticos para el presente histórico.

Respecto de este primer interrogante, el marco de la reconfiguración de las derechas en el siglo XXI, nos limitamos a mencionar los trabajos de Daza y Vollenweider (2017) quienes realizan una compilación donde distintos investigadores de la región llevan a cabo una reconstrucción de las trayectorias de los hombres y las mujeres más influyentes de las derechas latinoamericanas actuales, entre ellos Mauricio Macri, Samuel Doria Molina, Michel Temer, Sebastián Piñera, Juan Manuel Santos, Guillermo Lasso y Jimmy Morales. Asimismo, señalamos que, en el último decenio proliferó una abundante literatura académica sobre los intelectuales y los think tanks de derecha como actores de importante gravitación en la esfera político-ideológica puesto que, en los inicios del siglo XXI, han adquirido una relevancia central en la construcción de campañas políticas como también de candidatos; en la elaboración de discursos políticos y consignas, y en la reconfiguración del lenguaje que han adquirido las derechas: "los nuevos think tanks, sin vínculos orgánicos con los partidos políticos, proveen políticas «llave en mano» y cuadros técnicos a las fuerzas con posibilidades de acceder al gobierno." (Vommaro, 2014: 59).

Otro elemento a destacar, es que estos actores funcionaron (y funcionan) como medios y fuentes de financiamiento a través de políticas institucionales (Prego y 
Grassetti, 2017: 123). Es decir, los think tanks han tenido un rol activo en la elaboración de estrategias de acción e intervención configurándose como actores políticos, condicionando la agenda política y pública de los gobiernos de la región. Por cuestiones de espacio y objeto no los desarrollaremos, pero cabe mencionar entre los trabajos más destacados que abordan el tema y que mantienen una perspectiva regional y comparada los estudios de Fischer y Plehwe, 2013; Acuña, 2009; Balarin, Masi, Vera, González, Servín y Peres, 2016; Botto 2011; Giordano y Soler 2017.

El segundo interrogante se centra en la representación y se traduce en la siguiente pregunta ¿Es la derecha la forma política-ideológica que asumen los intereses de las clases dominantes?

Históricamente, mientras que las derechas han sido relacionadas con las clases dominantes, casi siempre caracterizadas como reaccionarias, las izquierdas fueron consideradas afines a los sectores más progresistas de la sociedad, entre ellos, las clases medias urbanas, los intelectuales y el sindicalismo. Sin embargo, esta cuestión no es fácil de abordar, especialmente si tenemos en cuenta que la relación entre clase e ideología no permite una traslación mecánica, es decir, una correspondencia automática entre intereses de clase y propuesta política-ideológica, más bien, concurren múltiples mediaciones entre ambos planos.

En este sentido, José Luis Romero (1970) advierte que es un error común asimilar la derecha a la burguesía y reprime esta decisión metodológica por considerarla inapropiada en el caso particular de Latinoamérica, donde el concepto burguesía es equívoco y se desconoce su contenido: "es bien sabido, en cambio, que no hemos precisado bien los contenidos del concepto "burguesía", y si aceptamos la asimilación no hacemos en rigor más que trasladar el problema del concepto "derecha" al concepto burguesías"2 (Romero, 1970:24). Para fortalecer su tesis afirma que existen grupos que son estrictamente ideológicos; tales son los casos de la clase media conformista, para

\footnotetext{
${ }^{2}$ Es preciso soslayar las condiciones de producción del trabajo de Romero. La discusión, por parte de la llamada teoría de la dependencia y el marxismo latinoamericano, en torno al carácter feudal o capitalista de las sociedades latinoamericanas estaba en su punto de mayor efervescencia. En este sentido, el concepto de burguesía como sujeto histórico despertaba amplios debates. Podemos suponer que la utilización del término en ese contexto hubiese sido, por lo menos, contraproducente para centrar el debate en torno a las derechas latinoamericanas.
} 
quienes el mantenimiento del orden significa garantía de estabilidad, o los grupos populares de mentalidad paternalista.

El autor también critica a quienes asimilan el concepto de clase dominante a derecha, dado que, por su propia constitución, aquella ha adquirido un comportamiento político confuso. Por estas razones advierte la necesidad de evitar definiciones simplistas y atenerse a los resultados de investigaciones empíricas. En rigor, su propuesta consiste en el estudio del fenómeno a partir de dos criterios: el político (quienes han hecho un uso autoritario del poder inscrito en la mentalidad liberal) y socioeconómico (quienes defienden el mantenimiento de las estructuras socioeconómicas y socioculturales). Ninguno de ellos es suficiente por sí mismo, sino que deben ser complementarios (pp.28).

Otros intelectuales plantean una relación más directa entre clases dominantes y derechas, discutiendo directamente con los postulados de José Luis Romero. A pesar de ser tributarios de tradiciones metodológicas y teóricas disímiles destacamos, dentro de este grupo, los trabajos Rodríguez Araujo, Waldo Ansaldi, Barry Cannon, José Jonás Duarte da Costa y Virginia Fontes. En ellos, la pregunta por la representación se salda en un análisis que repone la perspectiva estructural y resalta el antagonismo de clase como fundamento de la disputa político-ideológica.

Desde una perspectiva marxista, para Rodríguez Araujo (2004) las derechas se vinculan a las clases dominantes y sus intereses fundamentales para producir y reproducir su poder y, por lo tanto, reproducir la estructura de clases. El autor afirma que esta estructura supone la relación antagónica dominante-dominado y, por lo tanto, la desigualdad:

"La estructura de clase impone límites para el acceso diferenciado a recursos en una sociedad y, por lo mismo, a capacidades también diferenciadas para actuar. Las clases dominantes han tenido y tienen claro que para mantener $y$ reproducir su poder y lograr sus metas y objetivos (en función de sus intereses) tienen que mantener y reproducir la estructura de clases que les permite ser dominantes [...] la derecha siempre estaría ligada de una forma u otra a los intereses fundamentales de las clases dominantes" (pp.23). 
Sostiene que las clases dominantes, para reproducir su poder, tienen que reproducir la estructura de clases. En este sentido, destaca que las formas de dominación pueden ser democráticas o autoritarias, de acuerdo con la cambiante correlación de fuerza nacional e internacional.

En la misma línea de análisis se insertan los trabajos de Waldo Ansaldi (2014 y 2017) que, como mencionamos más arriba, afirma que la derecha es la posición política de la burguesía. El autor denuncia la desaparición, en el análisis sociológico, del conflicto de clases e intenta reestablecer al sujeto en los debates contemporáneos sobre las derechas. A su vez, acusa a los estudios más recientes sobre la materia de estar desprovistos de una mirada histórica. La propuesta se vuelve fundamental, en tanto proposición teórica y política, puesto que inserta y revive el conflicto y el antagonismo como ejes principales del análisis.

La contribución de Cannon (2016) se emparenta con las propuestas anteriores, pero aborda la cuestión desde una tradición teórica diferente, retomando la teoría de las elites. Utilizando como marco de referencia el concepto de poder social de Michael Mann, asegura que la elite no solamente detenta poder económico, sino que, a su vez, reviste un poder ideológico, militar y transnacional. Sin embargo, para el autor no hay que dejar de lado que estas "son esencialmente actores de clase y de allí la necesidad del estudio de la lucha de clase" (pp. 27-la traducción es propia-). Al desarrollar un esquema teórico que articula el enfoque económico estructural e ideológico propone retomar teóricamente los estudios gramscianos de la hegemonía.

Por último, reponemos dos propuestas que devienen fundamentales dado que articulan el estudio de clase con la perspectiva geopolítica. El primero de ellos es el trabajo de José Jonás Duarte da Costa (2010), quien afirma que las derechas son la expresión de las burguesías imperialistas bajo el comando de Estados Unidos. Así, las derechas en esta nueva fase geopolítica han ganado, en palabras del autor "contornos de verdad absoluta y han reestructurado su ofensiva ideológica y cultural bajo nueva dimensiones y propósitos, reelaborando y revalorizando viejos paradigmas" (pp.60-la traducción es nuestra-). 
Por su parte, Virginia Fontes (2010) considera que la base para cualquier definición de derechas bajo el sistema capitalista debe tener en cuenta el espectro social:

\begin{abstract}
"que agrega a los defensores en la sociedad de la gran propiedad, lo que ya de principio demarca que en la derecha se pueden encontrar propietarios de modalidades y extracciones sociales diversas, como terratenientes, industriales, comerciantes, banqueros, accionistas, especuladores, pequeños propietarios de bienes corrientes, etc." (pp.77 -la traducción es propia-).
\end{abstract}

En línea con Duarte da Costa, la autora nos insta a no pasar por alto que el foco central de la derecha en la sociedad capital-imperialista contemporánea es la defensa de la gran propiedad, de la propiedad del capital.

Como hemos podido observar, los interrogantes sobre la representación y la composición han dado lugar a diversas posturas que reivindican la pregunta por los sujetos en el estudio de las derechas latinoamericanas. Ello reviste implicancias teóricas y políticas, dado que presupone resaltar el carácter antagónico de los intereses de clase y el conflicto como factor inherente a toda relación social. Sin embargo, creemos que aún queda la tarea de explorar cuáles son los puentes posibles entre el plano políticoideológico y el económico-estructural, donde las relaciones entre uno y otro no son estrictamente lineales y ejercen múltiples condicionamientos.

A continuación, nos abocaremos al tercer núcleo de debate en torno a la especificidad de las "nuevas" derechas latinoamericanas: su compleja relación con las actuales democracias representativas.

\title{
3. Derechas y democracia
}

Derecha y democracia supone una relación compleja que suscita contradicciones inherentes de todo tipo y orden, y que ha estimulado profundos y profusos aportes teóricos en el campo de las ciencias sociales. El interrogante del cual partimos es el siguiente: ¿Existe una derecha democrática? O, como plantea Waldo Ansaldi (2007) “¿Por qué las clases dominantes que levantan la democracia liberal como principio de legitimidad de la construcción de su poder institucionalizado terminan generando 
regímenes escasamente democráticos cuando no francamente dictatoriales?". Para eso es preciso problematizar ambos conceptos (derechas y democracia) advirtiendo un elemento común que los atraviesa: su carácter polisémico.

Desde una mirada histórica de mediana duración podemos advertir cómo se configura la democracia en América Latina -principalmente en el Conos Sur- a partir de las transiciones de la década del ochenta tras el fin de las Dictaduras Institucionales de las Fuerzas Armadas (FFAA) y su vinculación con la derecha. En este período histórico, la democracia devino en el instrumento principal de legitimación del orden político, asumiendo un carácter netamente instrumental y procedimental (como democracia política) y las derechas suscribieron a este cambio. De esta manera, emerge la idea de una "nueva" derecha que buscaba distanciarse de la derecha autoritaria que había apoyado las dictaduras latinoamericanas: "Llama la atención porque aparecen vestidas con ropajes que no son lo que habían adoptado en el pasado, en particular en los años 70, cuando eran francamente autoritarias e incluso amañadas al terrorismo de Estado" (Giordano, 2014:49).

Uno de los primeros trabajos que lo problematiza es Hinkelammert en “Democracia y nueva derecha en América Latina” (1988) para quien la década del ochenta supuso para América Latina una ola de democratización y reconoce una nueva derecha que afirma la democracia desde una dimensión netamente instrumental. Esta nueva derecha, ante los cambios históricos suscitados, busca asegurar el poder originado en la dictadura, pero bajo formas democráticas. Como advierte Giordano (2014) es a partir de 1980 cuando las derechas aparecen como "abanderadas de la democracia representativa" (pp.50). Ansaldi y Soler (2015) enfatizan en la adhesión de las derechas a la democracia a partir de la década del ochenta: "el consenso ideológico gira en torno a la democracia como fuente de legitimidad del orden político en la región" (p.16). Asimismo, para estos autores, fue de importancia mayúscula la destrucción de los movimientos populares y revolucionarios de la década del sesenta y setenta, factor que garantizó que las derechas opten por la democratización (pp.17).

La democracia es un concepto polisémico y, pese a que el objetivo de ese apartado es su vinculación con las derechas, suscribimos al problema que nos propone Waldo Ansaldi ante los estudios reduccionistas a la dimensión politológica: "La democracia es 
un régimen político, sí, pero en una sociedad dividida en clases, como las nuestras, es también, y sobre todo, una forma de dominación político-social de clase. El contenido y los mecanismos de esa dominación difiere según la clase, e incluso la fracción de clase, que detenta el poder" (2007:36). El problema con la democracia es su relación con la desigualdad, dado que, desde una mirada filosófica y descriptiva, es una contradicción que exista igualdad política en el marco de la desigualdad económica y social, problema que se profundizó tanto en la década de los noventa en el marco de los gobiernos neoliberales como en la actualidad, ante el despliegue de gobiernos de derecha y la aplicación de políticas económicas regresivas. De allí la necesidad de problematizar la relación democracia y capitalismo; y de reconocer el problema fundamental: el poder (quién lo posee, detenta o ejerce, cómo lo ejerce y a favor de quién) (Ansaldi, 2007:37). Tal como sostiene Velasco (2006) la democracia puede contribuir a preservar o legitimar la desigual distribución del poder socioeconómico.

Como ya hemos advertido, a partir de la crisis del neoliberalismo, y la crisis política y de gobernabilidad desatada hacia fines de los noventa y principios del dos mil, asistimos a una reconfiguración de las democracias en distintos países América Latina, que comienzan a adquirir un carácter social e inclusivo, a partir de las mencionadas experiencias de gobiernos posneoliberales y/o progresistas. Este cambio epocal conllevó a la reconfiguración de las estrategias de las derechas. En ese sentido resaltamos, especialmente, la contribución de Juan Pablo Luna y Cristobal Rovira Koltwasser (2016) quienes llevaron a cabo una clasificación las derechas a partir de sus estrategias de acción e intervención: la derecha no electoral, la derecha electoral no partidaria y la derecha partidaria.

Respecto de la primera estrategia que señalan los autores, remite a aquellas acciones no electorales que logran movilizar y que emplean distintos recursos con capacidad de presionar y condicionar a los gobiernos posneoliberales. Entre ellas, destaca el lobby sobre los distintos organismos del Estado; el auspicio en medios de comunicación como así también la generación de los mismos; y también la promoción de actores colectivos que tengan presencia en el espacio público. Este último punto, guarda relación con el análisis que Raúl Zibecchi (2016) realiza de la "nueva derecha" en Brasil, definiéndola como una derecha sin partido que supo crear una cultura de 
protesta en la calle (por ejemplo, con las marchas contra la corrupción) logrando amplio apoyo de masas. Para Zibecchi, el problema radicó en atribuirle la potencialidad de este nuevo fenómeno a los medios, desconociendo que se trataba de una nueva fuerza social.

La segunda estrategia que distinguen los autores es la electoral no partidaria, partiendo del diagnóstico de la crisis de legitimidad que atraviesan en su gran mayoría los partidos y, por lo tanto, resulta más redituable postularse como ajenos y críticos al mundo de la política. La tercera estrategia remite a la formación de partidos políticos por parte de la derecha, lo que requiere una (re)construcción programática. Ansaldi y Soler (2015) proponen incorporar una cuarta clasificación: derechas que cooptan los partidos tradicionales para resguardarlos de sus propias crisis (como el caso de Horacio Cartes en Paraguay y Sebastián Piñera en Chile).

Para Juan Pablo Luna y Cristobal Rovira Koltwasser existen dos líneas de investigación: por un lado, la estabilización de la democratización del acceso al poder político y, por otro lado, el desarrollo de instituciones que buscan democratizar el ejercicio del poder político. La propuesta se vuelve vital para los análisis sobre las derechas en democracia puesto que afirman que la mayoría de los estudios se han centrado en el primero, sin embargo: "los estudiosos interesados en explorar el impacto de la derecha en la democracia en América Latina deben prestar más atención al segundo programa de investigación" (pp. 29) porque "las fuerzas de derecha tienen una responsabilidad importante en muchos de los síntomas de la baja calidad de las instituciones, tales como grupos de presión, el acceso desigual a la financiación de los partidos y la influencia de las redes tecnocráticas" (pp. 29). El aporte de los autores es invertir la perspectiva de análisis, evitando enfatizar qué ha hecho la democracia con las derechas, sino más bien qué han hecho las derechas con la democracia.

Hay otro elemento para profundizar en este interrogante: la modalidad que han adquirido los golpes de Estado del siglo XXI (denominados golpes blandos, golpes parlamentarios, neogolpismo). En un estudio comparativo desde la perspectiva de la sociología histórica, Soler (2015) analiza los casos de Haití (2004), Honduras (2009) y Paraguay (2012), y podríamos agregar el caso de Brasil (2016), como quiebres institucionales que exponen los nuevos formatos y las nuevas modalidades 
destituyentes y que conllevan a interrupciones de mandatos democráticos a partir de los mecanismos propios de la democracia liberal.

Como advierte Tokatlian (2012), el neogolpismo es una modalidad formalmente menos violenta, dirigida por civiles que pretenden violar la Constitución del Estado, pero preservando cierta apariencia institucional mínima: "tal ha sido la legitimidad lograda por los actores que emprendieron este nuevo tipo de golpismo, que en diferentes campos discursivos -intelectuales, periodísticos, etc.- se ha producido un desplazamiento semántico a la hora de nombrarlos, como si el quiebre de la voluntad popular y la soberanía política fueran más "blandos" o más "suaves" porque ya no son necesarias las armas de los militares ni la violencia física directa como metodología principal de los sectores dominantes para mantener el status quo" (Soler, 2015). De esta manera, su argumento de intervención es resguardar y/o recuperar el orden democrático.

\section{4. ¿Qué hay de nuevo en las derechas del siglo XXI?}

La producción académica existente sobre las nuevas derechas en el siglo XXI conllevó un importante esfuerzo por dar cuenta de la novedad del fenómeno. El análisis del corpus que conforma este trabajo nos impide hablar de una conceptualización acabada sobre las "nuevas derechas latinoamericanas" puesto que, como advierten Bohoslavsky y Boisard (2016), "resulta difícil y complicado ante la pluralidad de derechas ofrecer una definición teórica tajante" (pp.1). Sin embargo, se ha reconocido una línea de continuidad en dichas contribuciones puesto que todas ellas reconocen la necesidad de vincular la construcción del concepto en el marco de los procesos históricos.

En este sentido, Bohoslavsky y Bertonha (2016) apuntan a un estudio de casos desde una perspectiva histórica transnacional, abandonando la pretensión de conceptualizaciones amplias que den cuenta de la integralidad del fenómeno. Los autores centran su atención en las derechas del siglo XX con el interés de rastrear la genealogía de las derechas actuales.

Es bien interesante a su vez, la postura de Rodrigo Patto Sá Motta (2017) para quien "uno de los temas que mejor permite unir la constelación derechista es el 
anticomunismo, ahora combinado con ciertas dosis de antipetismo y antibolivarianismo" (pp. 80). En este sentido, el autor logra entablar un diálogo entre los componentes históricos de las derecha brasileña y latinoamericana.

Por su parte, López Segrera (2016) realiza una reconstrucción de las derechas latinoamericanas desde la mediana duración, reconociendo tres tipos: la derecha dictatorial (1964 a 1985) cuya principal característica fue la sumisión a Estados Unidos, la asociación con dictaduras militares y un irrestricto apoyo a la Doctrina de Seguridad Nacional (pp.78); la derecha neoliberal (1985 al 2000) caracterizada por la adhesión al Consenso de Washington, la construcción de una democracia estrictamente formal y un fuerte control de los medios de comunicación; y la "nueva derecha" que surge a partir del 2000 de la mano de Sebastián Piñera en Chile, Alvaro Uribe y Juan Manuel Santos en Colombia, Felipe Calderón y Enrique Peña Nieto en México, y Mauricio Macri en Argentina. Asimismo, forman parte de esta nueva generación de derechas desde la oposición Mauricio Rodas, en Quito, y Henrique Capriles y Henry Ramos Allup en Venezuela.

Para Verónica Giordano (2014) el concepto de derechas está sumergido en una realidad históricamente constituida y cambiante, y el concepto "nueva derecha" es producto de un proceso histórico que debe explicarse desde la mediana duración. De esta manera, debemos explorar los cambios, las rupturas $y$, sobre todo, las continuidades a partir de la década del ochenta, momento en el cual la región comienza a transitar un proceso de revalorización de la democracia representativa tras el fin de las dictaduras institucionales de las Fuerzas Armadas (FFAA). En este sentido, Sergio Morresi (2008) vislumbra, para el caso argentino, que más allá de sus cambios existe una continuidad entre la nueva y la vieja derecha dado que en ésta última se hallan sus orígenes con la que compartió ideas, hombres, planes y gobiernos en más de una ocasión (pp.9).

Waldo Ansaldi (2017) nos propone una mirada que supere la lectura netamente coyuntural a partir de la distinción entre lo orgánico y lo ocasional, siendo este último el que nos permite pensar el carácter "novedoso" de las derechas: "Así, no es lo mismo decir las "nuevas" derechas, que lo que tienen de nuevo las derechas. No es un juego de palabras, es una distinción fundamental. En el pensamiento y la concepción de derechas 
hay un núcleo duro que es permanente u orgánico: su posición respecto de la díada igualdad/ desigualdad. En cambio, lo que tienen de nuevo es puramente ocasional, accesorio, si bien es necesario prestar atención a algunas manifestaciones que bien podrían llegar a ser más o menos permanentes" (pp.26).

Entonces, nos resta preguntarnos ¿Qué hay de nuevo en las derechas del siglo XXI?

En primer lugar, retomando la propuesta teórica de Zizek (también desarrollada en Ansaldi y Soler, 2015 y Ansaldi, 2017) la novedad reside en la construcción de un lenguaje y un discurso pospolítico que, anclado en un paradigma posmoderno, no reconoce identificación o definición ideológica. Se desplazan las divisiones políticas e ideológicas entre la izquierda y la derecha; se desconocen los problemas colectivos para dar lugar sólo a las demandas específicas, que pasan a ser resueltas por técnicos y expertos. Lo individual desplaza a lo colectivo, lo público a lo privado, queriendo consagrar un proceso de licuación de la política: no hay más conflicto, solo impera el diálogo:

"Está claro: dicen no ser derecha, ni izquierda (tampoco centro); nada de mirar al pasado, solo hacia adelante, dejando de lado las ideologías (aunque, como bien se sabe, la no ideología es una forma encubierta de ideología) y, consecuentemente la absurda, mentirosa, falaz proposición 'Nosotros no nos enfrentamos con nadie'" (Ansaldi y Soler, 2015:25).

Es decir, se niega la política como herramienta de transformación.

Un segundo elemento es el cambio en el formato de representación política: consagran la institucionalización directa de la burguesía en el ejercicio de poder del Estado y del gobierno (Ansaldi, 2017). Puede observarse, a partir del acceso al poder de las derechas actuales en distintos países de la región, que son los empresarios locales los que asumen la dirección de los gobiernos. Los ejemplos más representativos son Sebastián Piñera en Chile, Horacio Cartes en Paraguay, Mauricio Macri en Argentina y Pedro Kuczynski en Perú. A su vez, se ha llevado adelante la incorporación de empresarios locales y/o burocracia empresarial en ministerios y áreas de gobiernos estratégicas para el desarrollo de la política económica en estos países. De esta manera, tienen el control directo (no ya mediado) para consolidar sus intereses de clase. 
Ambas variables nos acercan a un aspecto nodal de las derechas latinoamericanas: su profundo pragmatismo. La capacidad para adaptarse a nuevos formatos representativos, la enunciación de nuevos lenguajes, las alianzas con nuevos sectores, los cambios en su composición. Esta maleabilidad le ha permitido reconfigurarse pudiendo mantener un orden desigual o revertir procesos que han tenido tendencias igualitaristas.

\section{Reflexiones preliminares}

A lo largo del artículo advertimos que en el campo de las ciencias sociales existe una falencia respecto de una mayor sistematización de estudios referidos a las actuales derechas latinoamericanas, especialmente en torno a su conceptualización -sobre todo en comparación con los estudios existentes sobre las izquierdas-. Las producciones sobre las mismas, aunque subrepticiamente, se fueron desarrollando vis a vis con las cambios políticos y sociales acaecidos.

Como pudimos observar, surgieron en el campo académico núcleos de consenso y disenso en torno a las mismas. Advertimos que, en el corpus analizado, existe una matriz conceptual basada en los aportes de Norberto Bobbio que rescata la condición relación e históricamente situada de las derechas y las izquierdas y la apuesta por demostrar que su núcleo orgánico reside en la posición que mantienen respecto de la diada igualdad-desigualdad.

Por otro lado, expusimos que los núcleos que más debate suscitan son los referidos a la cuestión de los sujetos, traducido en las preguntas por la composición y la representación, y a la relación entre derechas y democracia. En cuanto a la primera, advertimos los límites de las posturas que plantean una visión estrictamente lineal, y, respecto al segundo debate, pudimos ver cómo mantienen una relación compleja, fluctuante y preñada de mutuas implicancias y condicionamientos.

Finalmente, nos abocamos a pensar el interrogante ¿Podemos hablar de nuevas derechas en América Latina? Tal como vimos a lo largo de nuestra indagación, existen posturas que sostienen el carácter novedoso de las derechas y aquellas que, aún capaces 
de visualizar el pragmatismo, advierten reconfiguraciones ante una esencia que permanece intacta, sin embargo, coincidimos con Verónica Giordano (2018) cuando advierte que es preciso evitar nombrar a las derechas del siglo XXI o derechas actuales con el calificativo "nuevas", puesto que

\begin{abstract}
"la afirmación de cualquier "novedad" debe sopesar la consulta acerca de la novedad respecto de ¿qué pasado? (par. 11). Como ya se ha dicho, aquí preferimos leer a las derechas actuales en una línea de continuidad respecto de las derechas ascendentes de los años ochenta y noventa, respecto de las cuales las "actuales" no son "nuevas" aunque sí lo sean los actores políticos que encarnan el proyecto neoliberal, cuyas particularidades a su vez deben leerse a la luz de las específicas condiciones histórico-espaciales de cada situación nacional"
\end{abstract}

Por lo tanto, creemos preciso continuar profundizando los estudios sobre las derechas en América Latina desde una perspectiva sociohistórica para avanzar hacia una conceptualización que permita dotar de capacidad heurística una categoría que es en sí misma compleja y polisémica y que nos permita abordar los procesos históricos con las herramientas necesarias para los tiempos que transcurren.

\title{
Bibliografía
}

ANSALDI, W. 2017. "Arregladitas como para ir de boda. Nuevo ropaje para las viejas derechas". Theomai, N³5. Disponible en http://www.redalyc.org/html/124/12452111003/

.2015. “La política, entre la pena y la canción. O la licuación de la política, un legado del neoliberalismo". Revista Temas y Debates $\mathrm{N}^{\circ} 29$, enero-julio. Disponible en http://rephip.unr.edu.ar/xmlui/bitstream/handle/2133/4960/Ansaldi\%20.pdf; sequence=2

.2014. "De la vox populi, vox deus, a la vox populi, vox mercatus. La cuestión de la democracia y la democracia en cuestión". Estudios, Centro de Estudios Avanzados № 31, enero-julio. Disponible en https://revistas.unc.edu.ar/index.php/restudios/issue/view/819

.2007. “La democracia en América Latina, un barco a la deriva, tocado en la línea de flotación y con piratas a estribor. Una explicación de larga duración". La democracia en América Latina, un barco a la deriva. Buenos Aires: Fondo de Cultura Económica ; SOLER L. 2015. "Derechas en América Latina en el siglo XXI". Carbone, R. y Soler, L. (Eds.) Des-cartes: Estampas de la derecha en Paraguay. Buenos Aires: Punto de Encuentro. 
BOHOSLAVSKY, E. 2012. "¿Qué es lo nuevo de la nueva derecha en Chile? Anticomunismo, corporativismo y neoliberalismo, 1964-1973". História Unisinos, Vol. 16 N 1, abril, pp. 5-14. Disponible en http://www.ungs.edu.ar/ms idh/wp-content/uploads/2012/09/unisinos2012.pdf

; BERTONHA J. 2016. "Las derechas sudamericanas: trayectorias, miradas y circulación". Circule por la derecha: Percepciones, redes y contactos entre las derechas sudamericanas, 1917-1973. Los Polvorines: Universidad Nacional General Sarmiento.

; y BOISARD, S. 2016. "Las derechas en América latina en el siglo XX: problemas, desafíos y perspectivas". Nuevo Mundo Mundos Nuevos, Colloques, mis en ligne le 25 janvier. Disponible en http://nuevomundo.revues.org/68802

BOBBIO, N. 2014. Derecha e izquierda. Buenos Aires: Taurus.

CANNON, B. 2016. The right in Latin American. Elite power, hegemony and the struggle for the state. Nueva York: Routledge.

CHÁVEZ, D.; RODRÍGUEZ GARAVITO C.; BARRET P. 2008. La nueva izquierda latinoamericana. Madrid: Catarata.

DI TELLA, T. 2004. Coaliciones políticas: ¿existen derechas e izquierdas? Buenos Aires Capital Intelectual SA.

DUARTE DA COSTA, J. 2010. "A ofensiva da direita na batalha das ideias: Métodos e instrumentos". Palau, M. (Coord.). La ofensiva de las derechas en el Cono Sur. Asunción: Base IS. FONTES, V. 2010. "Velhas e remodeladas formas da direita no Brasil". Palau, M. (Coord.). La ofensiva de las derechas en el Cono Sur. Asunción: Base IS.

FUKUYAMA, F. 1992. El fin de la historia y el último hombre. Buenos Aires: Planeta GALLARDO, H. 2012. “¿Retorna la derecha en América Latina?”. Pensar América Latina, julio. Disponible en:

http://heliogallardoamericalatina.info/index.php?option=com content\&task=view\&id=278\&ltemid=1

GIORDANO, V. 2014. “¿Qué hay de nuevo en las «nuevas derechas»?”. Revista Nueva Sociedad $\mathrm{N}^{\circ}$ 254 , noviembre-diciembre.

Disponible

en

http://nuso.org/media/articles/downloads/4068 1.pdf

HINKELAMMERT, F. 1988. "Democracia y nueva derecha en América Latina". Revista Nueva Sociedad $\quad \mathrm{N}^{\circ} \quad 98, \quad$ noviembre-diciembre. Disponible en http://nuso.org/media/articles/downloads/1703 1.pdf

LACLAU, E. 2006. "La deriva populista y la centroizquierda latinoamericana". Nueva Sociedad № 205, septiembre- octubre. Disponible en http://www.nuso.org/upload/articulos/3381 1 
LÓPEZ SEGRERA, F. 2016. América Latina: crisis del posneoliberalismo y ascenso de la nueva derecha. Ciudad Autónoma de Buenos Aires: CLACSO

LUNA, JUAN P.; ROVIRA KALTWASSER, C. 2011. "Las derechas gobernantes en América Latina: hacia una caracterización preliminar". Lasaforum, volume xlii: issue 3. Disponible en http://lasa.international.pitt.edu/forum/files/vol42-issue3/Debates4.pd\&\#13;f 2014. The Resilience of the Latin American Right. Johns

Hopkins University Press: Baltimore

MCGEE DEUTSCH, S. 2005. Las derechas. La extrema derecha en la Argentina, el Brasil y Chile (1890-1929). Buenos Aires: Editorial de la Universidad Nacional de Quilmes.

MORRESI, S. 2008. La nueva derecha argentina: la democracia sin política. Los Polvorines: UNGS. MOTTA, R. 2017. "Giro a la derecha e impeachment: la crisis política de Brasil". En Revista Política Latinoamericana №5, Buenos Aires, julio-diciembre, p.77-85.

QUIROGA, H. 2010. “¿De qué hablamos cuando hablamos de izquierda hoy?”. Temas y Debates, Revista universitaria en Ciencias Sociales, Facultad de Ciencias Políticas y Relaciones Internacionales, Universidad Nacional de Rosario, № 20. Disponible en http://www.temasydebates.unr.edu.ar/index.php/tyd/issue/view/3

PREGO, F; GRASSETTI, J. 2017. Think tanks, intelectuales y derechas. El rol de la Fundación para el Análisis y los Estudios Sociales (Faes) en Venezuela y Argentina (2015-2017). Millcayac-Revista Digital de Ciencias Sociales, 4(7), 121-140.

RODRÍGUEZ ARAUJO, O. 2004. Derechas y ultraderechas en el mundo. México: Siglo XXI Editores.

ROMERO, J. L. 1970. El pensamiento político de la derecha latinoamericana. Buenos Aires: Paidós.

SADER, E. 2009. El nuevo topo, los caminos de la izquierda latinoamericana. Buenos Aires: Siglo XXI Editores- CLACSO.

SOLER, L. 2015. Golpes de Estado en el siglo XXI. Un ejercicio comparado, Haití (2004), Honduras (2009) y Paraguay (2012). Cadernos Prolam/USP 14 (26), p. 79-92. Disponible en https://uba.academia.edu/LorenaSoler

SOMER, M. 1996. ¿Qué hay de político o de cultural en la cultura política y en la esfera pública? Hacia una sociología histórica de la formación de conceptos. En Zona abierta, ISSN 02102692, № 77-78, p. 31-94.

SVAMPA, M. 2017. “Cuatro claves para leer América Latina”. En Revista Nueva Sociedad, N²68. Disponible en http://nuso.org/articulo/cuatro-claves-para-leer-america-latina/ 
TOKATLIAN, J. 2012. "El auge del neogolpismo", publicado en La Nación, 24 de junio. Disponible en: http://www.lanacion.com.ar/1484794-el-auge-del-neogolpismo

VELASCO, J. 2006. "Democratización y conflictos distributivos en América Latina". Ansaldi, Waldo (director). La democracia en América Latina, un barco a la deriva. Buenos Aires: Fondo de Cultura Económica.

VOMMARO, G. 2014. "«Meterse en política»: la construcción de PRO y la renovación de la centroderecha argentina”. En Nueva Sociedad, № 254, noviembre-diciembre, pp. 58-59.

ZIBECHI, R. 2016. "Las bases sociales de las nuevas derechas en Latinoamérica”. La Jornada de México, 19 de febrero. Disponible en http://www.jornada.unam.mx/2016/02/19/opinion/019a2pol 